\title{
CORRIGENDA
}

\section{Association of an X-chromosome dodecamer insertional variant allele with mental retardation}

RA Philibert, BH King, S Winfield, EH Cook, Y-H Lee, B Stubblefield, P Damschroder-Williams, C Dea, A Palotie, C Tengstrom, BM Martin, El Ginns. Mol Psychiatry 1998; 3: 303-309.

The sequence of the reverse primer on page 304 and Figure 1 were incorrect. The correct sequence for the reverse primer is as follows $\left(5^{\prime}\right.$ to $\left.3^{\prime}\right)$ :
GGGCTGTAGTCCAGCAGCTACCTG. The correct figure is shown below.

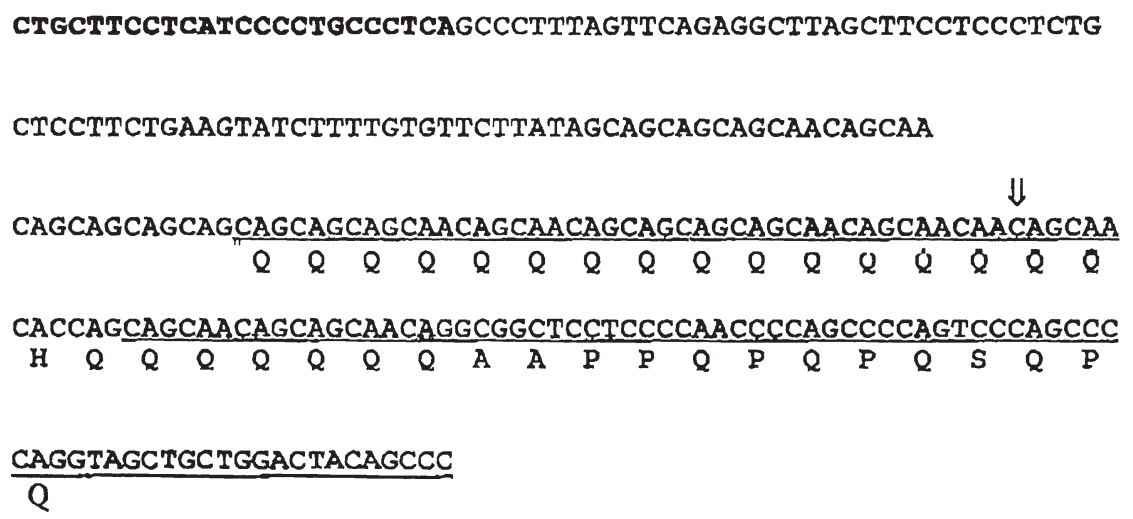

Figure 1

\section{Alpha synuclein is present in Lewy bodies in sporadic Parkinson's disease}

E Mezey, AM Dehejia, G Harta, N Tresser, SF Suchy, RL Nussbaum, MJ Brownstein, MH Polymeropoulos. Mol Psychiatry 1998; 3: 493-499.

In this paper, the name of one of the co-authors, Nancy Tresser, was inadvertently omitted from the original publication. The correct authorship is reproduced in full above.
Nancy Tresser's affiliation is Office of the Clinical Director, National Institute of Neurol ogical Disease and Stroke, National Institutes of Health, Bethesda, MD 20892, USA. 